Systematic Review

\title{
Particulate vs Non-Particulate Steroids for Transforaminal Epidural Steroid Injections: Systematic Review and Meta-analysis of the Current Literature
}

Jeetinder Kaur Makkar, MD, DNB'1, Preet Mohinder Singh, MD, DNB² , Divya Jain, MD'1, and Basavana Goudra, MD, FRCA, FCARSI ${ }^{3}$

From: ${ }^{2}$ Department of Anaesthesia, PGIMER, Sector 12, Chandigarh, India; ${ }^{2}$ Department of Anesthesia, Critical Care and Pain Medicine, All India Institute of Medical Sciences, New Delhi, India; ${ }^{3}$ Hospital of the University of Pennsylvania and Perleman School of Medicine, Philadelphia, PA

Address Correspondence: Dr. Jeetinder Kaur Makkar Department of Anaesthesia, PGIMER,

Sector 12, Chandigarh, India-160012

E mail: jeet1516@gmail.com

Disclaimer: There was no external funding in the preparation of this manuscript. Conflict of interest: Each author certifies that he or she, or a member of his or her immediate

family, has no commercial association (i.e., consultancies, stock ownership, equity interest, patent/licensing arrangements, etc.) that might pose a conflict of interest in connection with the submitted manuscript.

Manuscript received: 08-11-2015 Revised manuscript received: 11-08-2015

Accepted for publication: 01-18-2016

Free full manuscript: www.painphysicianjournal.com
Background: The efficacy of particulate and non-particulate steroids in patients receiving epidural steroid injections remains unclear.

Objective: The purpose of this meta-analysis was to compare the efficacy of particulate and non-particulate steroids in patients receiving epidural injections for radicular pain over 3 months.

Study Design: Systematic review and meta-analysis.

Methods: We reviewed PubMed, PubMed Central, Scopus, Central Register of Clinical Trials of the Cochrane Collaboration, Google Scholar, and Directory of open access journals for trials that compared efficacy of particulate steroid with non-particulate. A meta-analysis was performed on treatment related to mean change in visual analogue score (VAS) between the particulate and non-particulate steroids. Two authors independently reviewed the data for inclusion.

Results: Seven studies comprising 3,542 patients in the particulate group and 856 patients in the non-particulate group were included. Pooled mean maximum change of VAS was higher by $0.53(95 \% \mathrm{Cl}: 0.14$ to $0.92 ; P=0.007 ; 12=50.2 \%)$ in the particulate group compared to the non-particulate group. The non-particulate group had a larger proportion of patients with more than $50 \%$ pain relief than the particulate group [OR 0.81 (95\% Cl: 0.68 to $0.97, P=0.024)$.

Limitations: Limited number of trials that fit the inclusion criteria and were available for analysis.

Conclusions: As the use of particulate steroids seems to be associated with slightly better VAS scores only, clinicians need to weigh their clinical relevance in the light of complications and recent FDA recommendations on the use of particulate steroids.

Key words: Meta-analysis, particulate epidural steroids, non-partiuclate epidural steroids, efficacy, decrease in pain scores

Pain Physician 2016; 19:327-340

\section{D} D ack pain with a radicular component is a significant health problem affecting millions $(1,2)$. Treatment options include conservative management, epidural steroids, and surgery in a stepwise approach. Conservative management includes exercise, weight loss, and physiotherapy. Epidural steroids are used in patients who fail to respond to conservative management. Inflammatory cytokines released from a herniated disc cause chemical irritation of the nerve roots and hence result in radicular pain. 
Steroids decrease inflammation around the affected nerve, suppress ectopic discharge, and enhance blood flow to the ischemic nerve root thus leading to a decrease in pain (3-5).

The preparation of steroids used in the epidural space can be divided into 2 groups - particulate such as methylprednisolone, betamethasone, and triamcinolone; and non-particulate like dexamethasone phosphate. Particulate steroids have longer a duration of action due to a local depot effect resulting in continuous release of the active drug from the injection site over a long time period (6).

On the other hand non-particulate steroids are water soluble steroid with small particle size and limited aggregation (7). This results in rapid clearance from the spinal canal and a short duration of action (8). So one anticipates a long-lasting relief of symptoms in patients receiving epidural injection with particulate steroids compared to those who receive non-particulate steroids.

Though epidural steroids have been used in clinical practice for decades now, several case reports have documented potential complications like paraplegia secondary to spinal cord infarction associated with the use of particulate steroids (9-17). Occlusion of the segmental artery accompanying the nerve root by the particulate steroid or embolization of the particulate steroid through the vertebral artery are the possible etiologies involved $(18,19)$.

Only 2 studies have addressed the issue of the microscopic size of the particles within various steroid preparations $(8,19)$. Tiso et al $(19)$ found that particles in dexamethasone and betamethasone were rod like and lucent, whereas particles of methylprednisolone and triamcinolone were opaque and amorphous. Further, particles of methylprednisolone and triamcinolone coalesced into larger particles greater than $100 \mu \mathrm{m}$. These particles could occlude capillaries $(5-8 \mu \mathrm{m})$, metarterioles $(20-50 \mu \mathrm{m})$, and at times arteries $(>50 \mu \mathrm{m})$, resulting in infarction of large block of neural tissue supplied by that artery. Benzon et al (8) noted particles greater than $1000 \mu \mathrm{m}$ in size and it to faster precipitation of steroids. Shaking the solution before administration resulted in formation of small particles which coalesced and precipitated into a larger size on entering the vessel thus making it possible for any steroid size to enter and block a vessel of any size.

On the other hand, dexamethasone has a particulate size of less than $5 \mu \mathrm{m}$, the lowest density, and the least tendency for aggregation. In the literature, no se- rious neurological complication has been reported with use of dexamethsone. However, it has limited effectiveness in patients with radicular pain (20). This limited efficacy of dexamethasone when compared to particulate steroids remains a matter of concern.

Clinical studies evaluating the efficacy of different types of steroid injections have shown variable results without a definite conclusion. Few studies report statistically significant efficacy of particulate steroids over non-particulate $(21,22)$, while others fail to show any significant benefit $(23,24)$. Further there are variations in time intervals at which patients are followed and pain relief reported in these studies. The aim of this systematic review and meta-analysis was to compare the efficacy of particulate and non-particulate steroids in patients receiving epidural injections for radicular pain. The primary outcome of the meta-analysis was to compare the treatment related mean change in visual analogue score (VAS) between the particulate and nonparticulate steroids. The exploratory outcome was to compare the percentage of patients having more than $50 \%$ pain relief.

\section{Methods}

This meta-analysis was undertaken in accordance with the PRISMA (Preferred Reporting Items for Systematic Reviews and Meta-analyses) guidelines (25).

\section{Eligibility Criteria}

\section{Type of Studies}

All the randomized controlled trials, cohort studies, or retrospective studies of patients who received epidural steroids injection were considered.

\section{Participants}

Participants were adults with neck or back pain who received either a cervical or lumbar injection using one of the 3 approaches, i.e., transforaminal, interlaminar, or caudal.

\section{Study Intervention}

Patients in one arm received epidural injections with particulate steroids, whereas patients in the second arm received non-particulate steroids.

\section{Outcome Measures}

The primary outcome was to compare the treatment-related mean change in VAS with use of particulate and non-particulate steroids. We included only 
those studies which used VAS or NRS for pain assessment and had a minimum follow-up assessment at one month. In case of studies reporting pain in NRS, values were transformed into VAS. The exploratory outcome was to compare the percentage of patients having more than $50 \%$ pain relief with a minimum follow-up of one month. We did not limit the inclusion based on dose of steroids or number of injections.

\section{Exclusion Criteria}

Trials where injections were performed without the aid of fluoroscope.

Trials comparing the local anaesthetics with the epidural steroid injections.

\section{Information Sources and Search Methods}

Two authors (JK, DJ) independently searched PubMed, PubMed Central, Scopus, Central Register of Clinical Trials of the Cochrane Collaboration, Google Scholar, and Directory of open access journals for eligible studies using the various combinations of search words: epidural, steroid, particulate steroids, non-particulate steroids, triamcinolone, betamethasone, dexamethasone, back pain. The bibliographies of all the selected articles were reviewed to find possible additional articles that might have been missed in the initial search.

\section{Search Strategy}

Studies comparing a particulate steroid with a nonparticulate steroid (prospective or retrospective) administered either through a lumbar or cervical route using one of the 3 approaches, i.e., transforaminal, interlaminar, and caudal route, published either as full articles or meeting abstracts (in peer-reviewed journals) were considered.

Steroids considered for this review included methylprednisolone, dexamethasone, betamethasone, and triamcinolone.

The aforementioned reviewers performed an independent assessment of the full text of articles assessed for eligibility and made individual decisions whether to include the potential study in the analysis. In case of any disagreement, the opinion of a third researcher was taken into account.

\section{Validity Assessment}

Formal quality assessment for bias in studies was carried out by an independent investigator in accordance with the guidelines of the Cochrane Collaboration (Appendix 1) (26). Studies were not excluded based on their clinical relevance.

\section{Data Extraction}

Required data was collected from the full text of the articles and was tabulated in a Microsoft Excel spreadsheet. Initial data extraction from the eligible trials was done by one of the authors, JK. Data was cross-checked independently by the other 2 co-authors, P.M.S. and D.J. Statistical analysis was performed by P.M.S.

Data collected from each study included name of first author, study design, year of publication, country of origin of study, dose of steroid, baseline VAS/NRS and VAS/NRS during the follow up-period, percentage of patients having more than $50 \%$ pain relief, mean number of epidural injections, baseline ODI and percentage of change in ODI after epidural injection. For trials documenting VAS/NRS at various time intervals, we analyzed the lowest values post treatment, allowing us to measure the highest therapeutic effect achieved in each group.

\section{Quality of Evidence}

Quality of evidence for the primary outcome was assessed as per the American Society of Interventional Pain Physicians' (ASIPP) grading to assign best evidence synthesis (Appendix 2) (27).

\section{Statistical Analysis}

Comprehensive Meta-analysis Version 2 (Biostat Inc.) was used for the statistical analysis of the pooled data. Fixed-effect modeling followed by random-effects modeling (after assessment of heterogeneity with fixed modeling) were used to perform meta-analysis. Wherever heterogeneity was found to be higher resulting values are reported from random effect modeling. For continuous data, means and standard deviation (SD) values of VAS were extracted for both groups, a mean difference was computed at the study level and weighted mean difference was calculated in order to pool the results across all studies. If the values were reported as median and interquartile range (IQR) or total range of values, the mean value was estimated using the median and the low and high end of the range for samples smaller than 25; for samples greater than 25, the median itself was used. SD was estimated from the median and the low and high end of the range for samples smaller than 15 , as range/4 for samples from 15 to 70 , and as range/6 for samples more than 70 . If only an IQR was available, SD was estimated as IQR/1.35 $(28,29)$.

The extent of heterogeneity in between the trials was quantified using the $\mathrm{I}^{2}$ statistic. $\mathrm{I}^{2}<40 \%$ was considered unimportant; $30 \%$ to $60 \%=$ moderate het- 
erogeneity, $50 \%$ to $90 \%$ = high heterogeneity. Results were expressed as mean difference with $95 \%$ confidence interval $(\mathrm{Cl}) . P<0.05$ was considered statistically significant. Potential publication bias was assessed using a funnel plot and evaluated using the Egger's test.

\section{Search Results}

Figure 1 shows the search results and study selection flow chart. The preliminary search yielded 312 studies from the aforementioned database. Duplicates obtained by individual researchers during their independent review of the database were removed electronically using Endnote. On final evaluation, 8 trials (21-24,30-33) and 4 abstracts (34-37) published in scientific proceedings of peer reviewed journals fulfilled the inclusion criterion. One study and 4 abstracts did not measure the desired primary outcome parameters and were excluded from analysis. The primary outcome

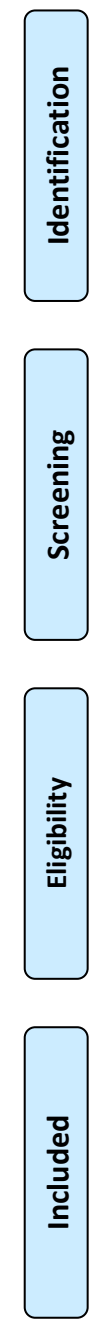

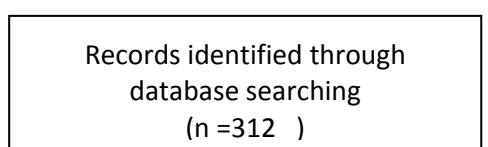

$(n=312)$
Additional records identified through other sources $(n=0)$
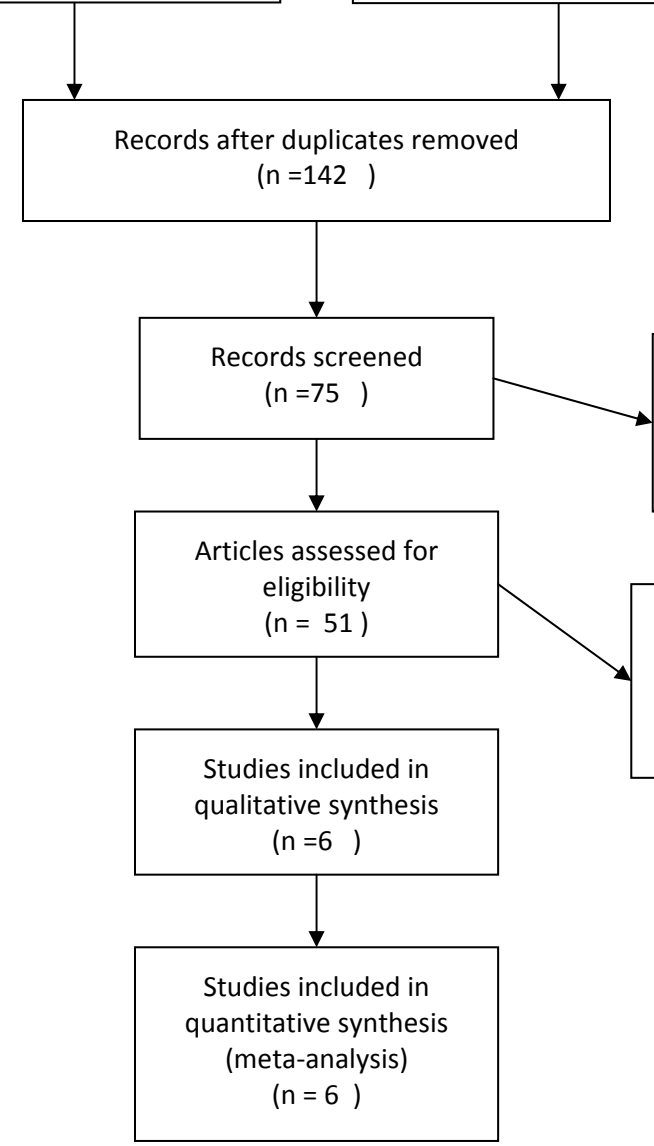

Records excluded ( $n=24$ )

Compared different doses, compared with LA or saline

Articles excluded, with reasons $(n=45)$

two different types of steroids, inadequate data

From: Moher D, Liberati A, Tetzlaff J, Altman DG, The PRISMA Group (2009). Preferred Reporting /tems for Systematic Reviews and MetaAnalyses: The PRISMA Statement. PLoS Med 6(6): e1000097. doi:10.1371/journal.pmed1000097

For more information, visit www.prisma-statement.org.

Fig. 1. Flow chart showing the search results of the meta-analysis. 
data of the highest post-treatment VAS drop was available for 3,542 and 856 patients in particulate and nonparticulate groups, respectively of the 7 studies included (21-24,31-33).

\section{Trials, Participants, and Interventions (Table 1)}

Out of the 7 studies included in the trial, 4 were prospective randomized trials $(21,23,24,32)$ and 3 were retrospective analyses $(22,31,33)$. Two studies enrolled patients with cervical epidural injections $(24,33)$ while 5 had patients with lumbar epidural injections $(21-23,31,32)$.

Among the particulate steroids, triamcilone 40 -
$80 \mathrm{mg}$ was used in 4 trials whereas methylprednisolone was used in 2. Dexamethasone in a dose range of 10 - $15 \mathrm{mg}$ was the most commonly used non-particulate steroid except one in which aqueous betamethasone (15 mg) was used.

Functional outcome after epidural steroid injection was assessed in 4 trials. Out of these, 3 trials used a validated Oswestry disability index, while Dreyfuss et al (24) used a patient specified outcome measure.

Only a single trial, which compared the complication rate between the particulate and non-particulate group, did not report any complication in either group (31).

Table 1. Summary of the trials, participants, interventions and results.

\begin{tabular}{|l|c|c|c|}
\hline \hline Author (year) & Design & Approach & Patients enrolled \\
\hline Kennedy D (2014) & Prospective, multicenter & Transforaminal (lumbar) & $(37: 41)$ \\
\hline Kim D (2011) & Prospective, single center & Translaminar (lumbar) & $(30: 30)$ \\
\hline El Yahchouchi CE (2013) & Retrospective & Transforaminal (lumbar) & $(1151: 481)$ \\
\hline Dreyfuss (2006) & Prospective, multicenter & Transforaminal (cervical) & $(15: 15)$ \\
\hline Shakir A (2013) & Retrospective & Transforaminal (cervical) & $(220: 221)$ \\
\hline Noe C (2003) & Retrospective & Transforaminal (lumbar) & $(25: 15)$ \\
\hline Park C (2010) & Prospective & Transforaminal (lumbar) & $(53: 53)$ \\
\hline
\end{tabular}

\begin{tabular}{|c|c|c|}
\hline Intervention & Outcome & Results \\
\hline $\begin{array}{l}\text { Particulate gp- } 1.5 \mathrm{~mL} \text { : triamcinolone }(40 \mathrm{mg} / \\
\mathrm{mL}) \\
\text { Non-particulate gp-1.5ml dexamethasone } \\
(10 \mathrm{mg} / \mathrm{mL})\end{array}$ & $\begin{array}{l}\text { number of injections, surgical rates, pain } \\
\text { scores, Oswestry disability index } \\
\text { Time frame - 2weeks/3months/6months }\end{array}$ & $\begin{array}{l}\text { No significant difference in pain scores } \\
\text { and functions in between } 2 \text { groups. } \\
\text { Significant more injections were required in } \\
\text { dexamethasone group. }\end{array}$ \\
\hline $\begin{array}{l}\text { Particulate gp- } 80 \mathrm{mg} \text { methylprednisolone } \\
\text { Non-particulate gp-15 mg dexamethasone. }\end{array}$ & $\begin{array}{l}\% \text { change in pain score, } \% \text { patients } \\
\text { with decreased pain, days of follow up, } \\
\text { complications } \\
\text { Time frame - } 1 \text { month }\end{array}$ & $\begin{array}{l}\text { Lesser decrease in pain scores in } \\
\text { dexamethasone group compared to } \\
\text { methylprednisolone group. No difference in } \\
\text { mean days of follow up. No complications }\end{array}$ \\
\hline $\begin{array}{l}\text { Particulate gp- } 80 \mathrm{mg} \text { triamcinolone }(40 \mathrm{mg} / \\
\mathrm{ml}, 2 \mathrm{~mL}) \\
\text { Non-particulate gp-10 mg dexamethasone. } \\
(10 \mathrm{mg} / \mathrm{mL})\end{array}$ & $\begin{array}{l}\text { Pain scores, successful pain relief }(<50 \% \\
\text { reduction in pain score }) \\
\text { Time frame }-2 \text { weeks } / 2 \text { months }\end{array}$ & $\begin{array}{l}\text { Dexamethasone was superior to triamcinolone } \\
\text { in both pain relief and functional outcome }\end{array}$ \\
\hline $\begin{array}{l}\text { Particulate gp-60mg triamcinolone } \\
\text { Non-particulate gp-12.5 mg dexamethasone }\end{array}$ & $\begin{array}{l}\text { Pre and post procedural pain scores, } \\
\text { functional outcome. } \\
\text { Time frame - } 4 \text { weeks }\end{array}$ & $\begin{array}{l}\text { No significant difference in pain scores and } \\
\text { functions in between } 2 \text { groups. }\end{array}$ \\
\hline $\begin{array}{l}\text { Particulate gp- } 40 \mathrm{mg} \text { triamcinolone } \\
\text { Non-particulate gp- } 15 \mathrm{mg} \\
\text { dexamethasone }(10 \mathrm{mg} / \mathrm{mL})\end{array}$ & $\begin{array}{l}\text { Mean reduction in pain scores } \\
\text { (self reported pain score), number of } \\
\text { injections } \\
\text { Time frame - } 4 \text { weeks }\end{array}$ & $\begin{array}{l}\text { No significant difference in mean reduction in } \\
\text { pain scores in between } 2 \text { groups. }\end{array}$ \\
\hline $\begin{array}{l}\text { Particulate gp- } 80 \mathrm{mg} \text { methylprednisolone } \\
\text { Non-particulate gp-15 mg non depot } \\
\text { betamethasone }\end{array}$ & $\begin{array}{l}\text { Mean reduction in pain scores and disability } \\
\text { index } \\
\text { Time frame }-4 \text { weeks }\end{array}$ & $\begin{array}{l}\text { Significant improvement noted in depo } \\
\text { methylprednisolone compared to aqueous } \\
\text { betamethasone }\end{array}$ \\
\hline $\begin{array}{l}\text { Particulate gp- } 40 \mathrm{mg} \text { triamcinolone } \\
\text { Non-particulate gp- } 7.5 \mathrm{mg} \text { dexamethasone }\end{array}$ & $\begin{array}{l}\text { Pain scores, } \% \text { change in pain score Oswestry } \\
\text { disability index } \\
\text { Time frame - } 4 \text { weeks }\end{array}$ & $\begin{array}{l}\text { Dexamethasone was superior to triamcinolone } \\
\text { in short term pain relief }\end{array}$ \\
\hline
\end{tabular}




\section{Primary Outcome}

\section{Maximum Difference in Mean VAS at Any Time Interval}

Six trials reported data within 2 months and one reported data at 3 months. Pooled mean of VAS was higher by $1.023\left(95 \% \mathrm{Cl}: 0.29\right.$ to $1.76 ; P=0.007 ; I^{2}=$ $90.59 \%$ ) in the particulate group compared to the nonparticulate group (Fig. 2). Subgroup analysis evaluating the pooled values after grouping into lumbar and cervical injections showed pooled estimates of VAS change being higher in the particulate group compared to the non-particulate group by 1.22 (95\% Cl: 0.25 to $2.18 ; 1^{2}$ $=92.522 \%$ ) in the lumbar region (Fig. 3). In the cervical region, only 2 studies were available for subgrouping. The particulate group showed a higher fall in VAS than the non-particulate group [OR: $0.44(95 \% \mathrm{Cl}: 0.70$ to $1.57 ; 1^{2}=56.015 \%$ ) (Fig. 4).

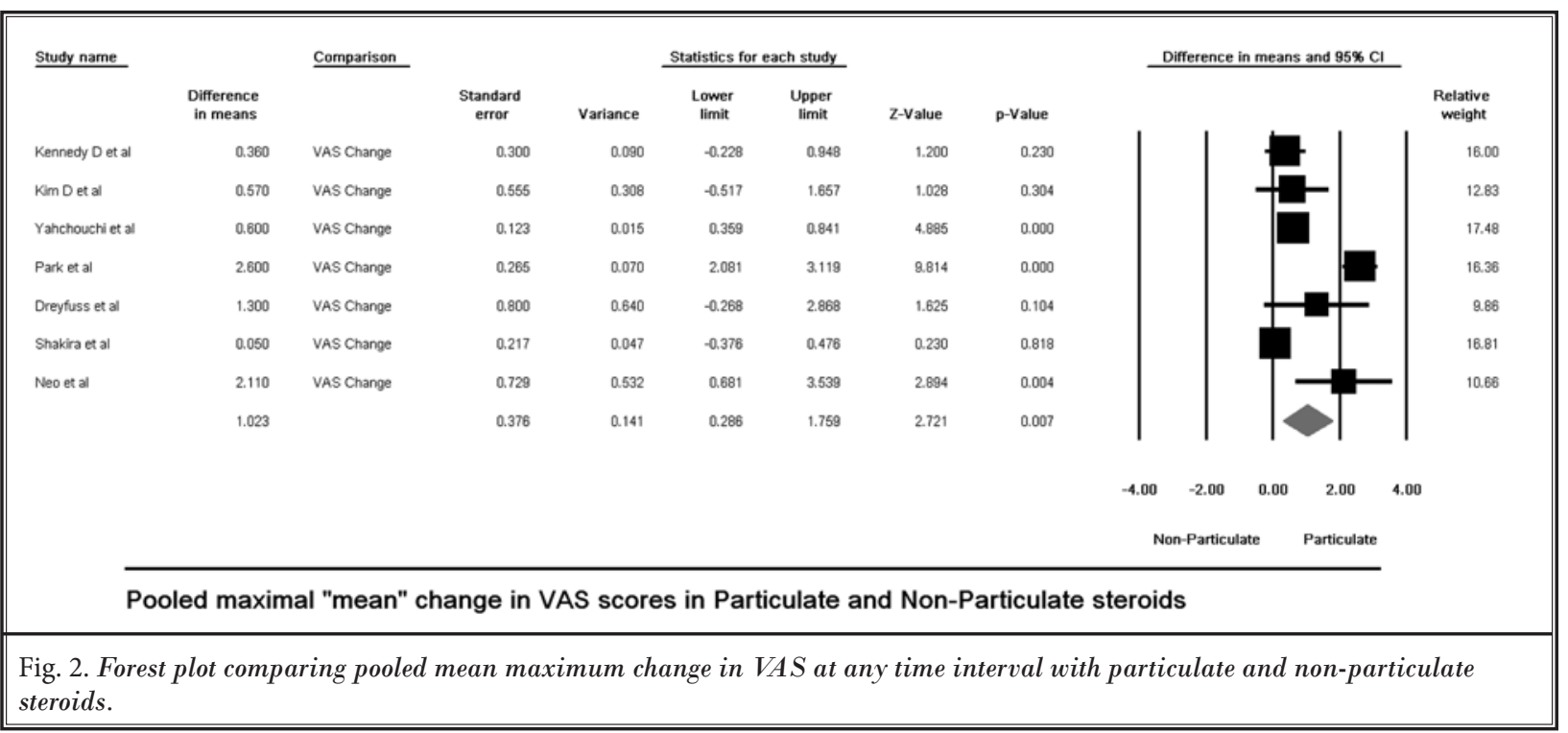

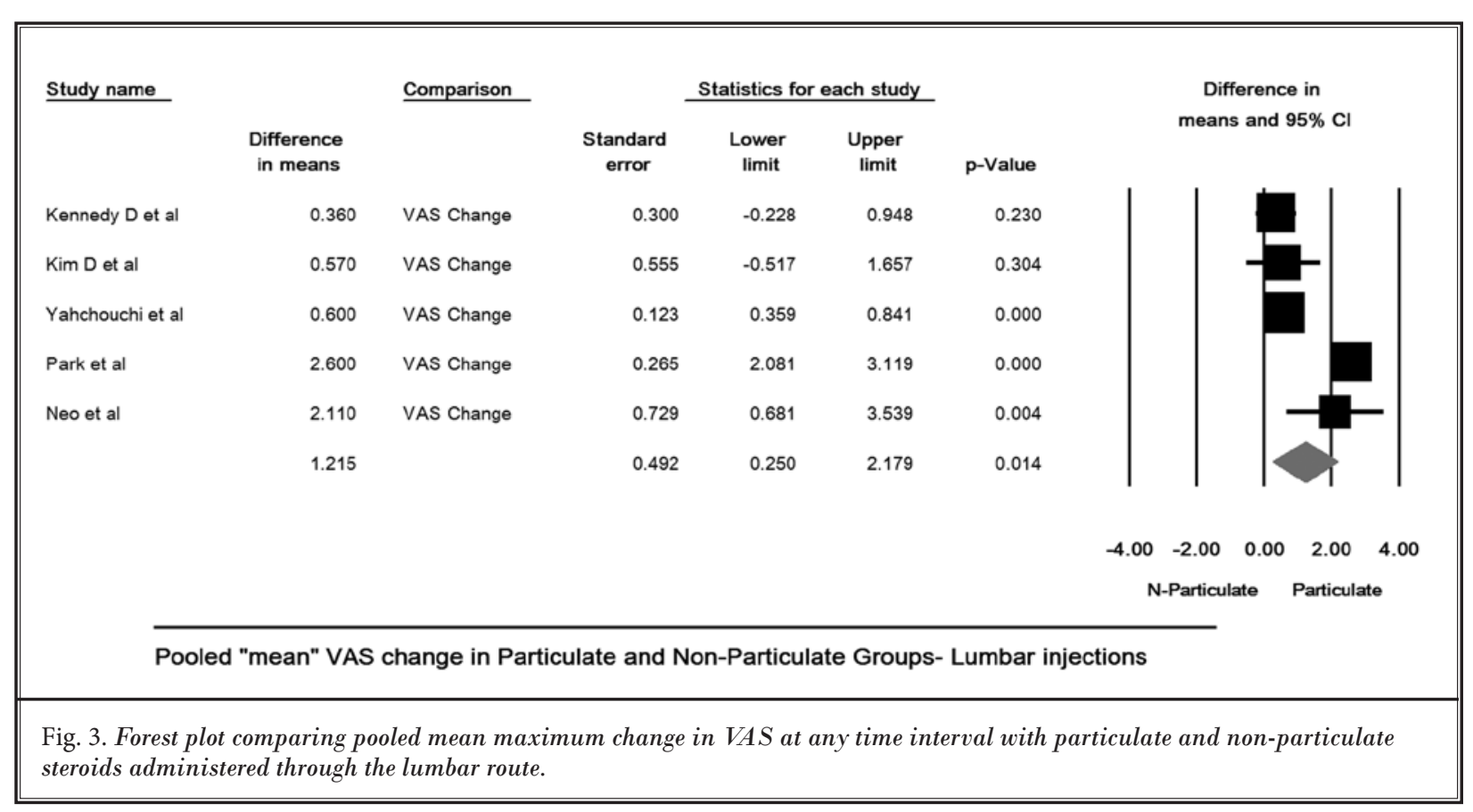


Particulate vs Non-Particulate Steroids for Transforaminal Epidural Steroid Injection

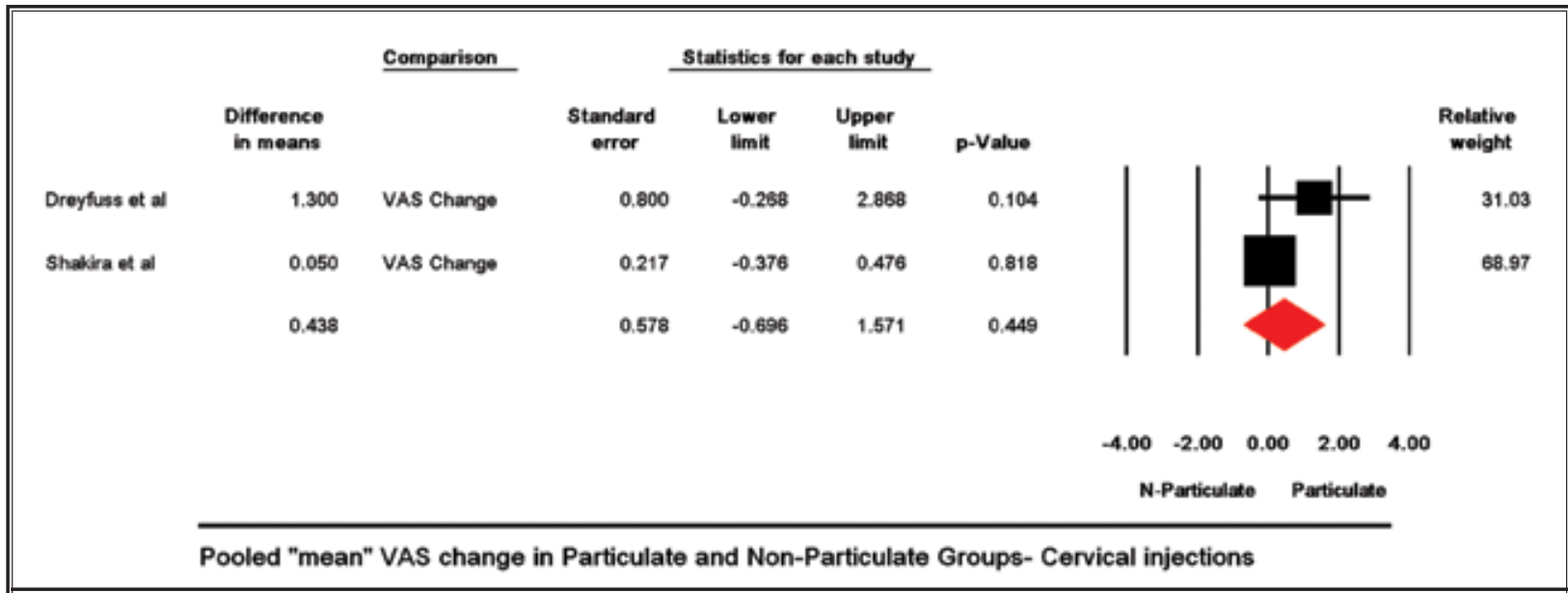

Fig. 4. Forest plot comparing pooled mean maximum change in VAS at any time interval with particulate and non-particulate steroids administered through the cervical route.

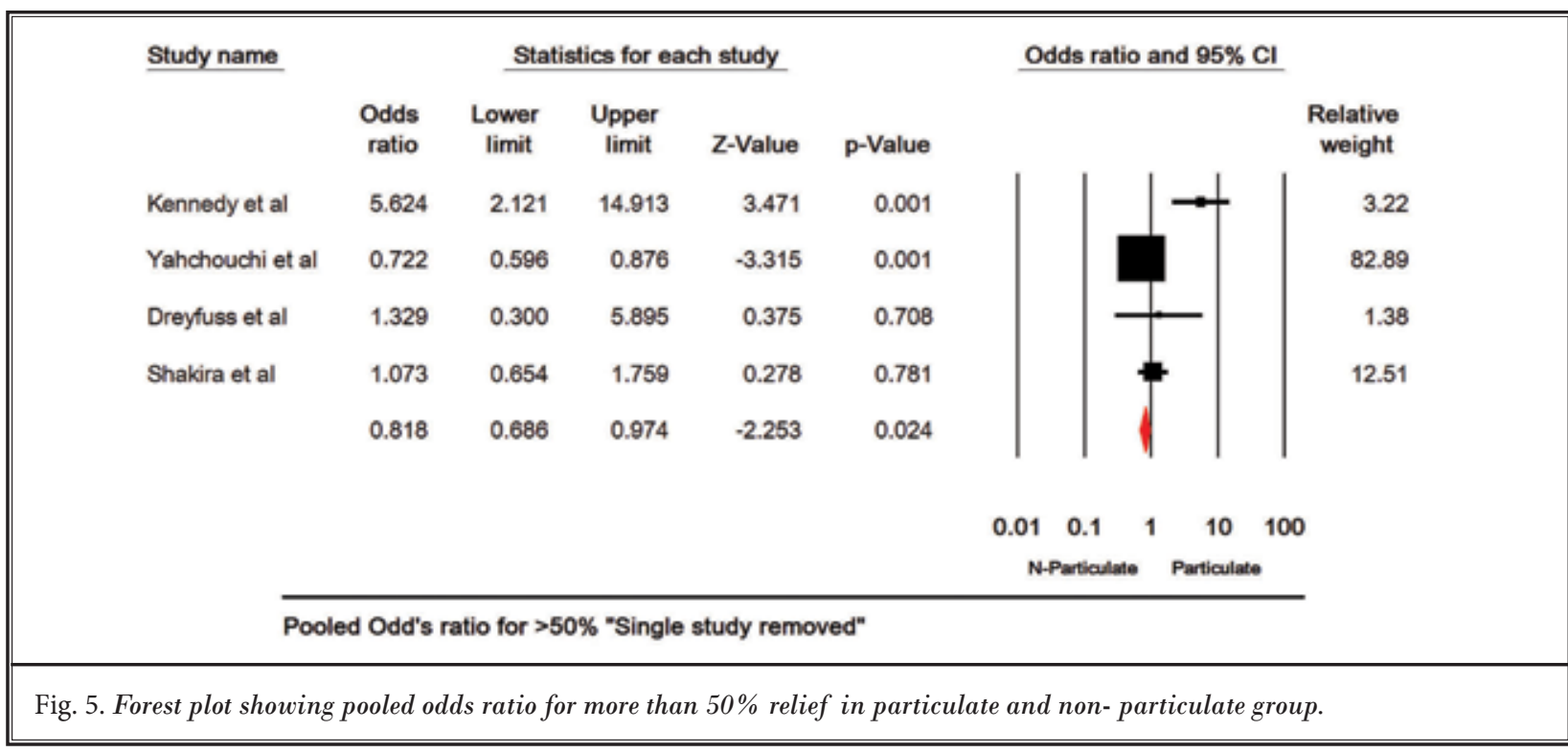

\section{Exploratory Outcome}

\section{More than $50 \%$ Pain Relief}

Five trails $(21,24,31-33)$ documented patient numbers with more than $50 \%$ relief during the course of treatment. In the particulate group, pooled values included a total of 4,298 patients of which 1,856 patients had at least $50 \%$ or more pain relief. In the non-particulate group, data for 811 patients was available of which 329 showed relief of $50 \%$ or more. The non-particulate group had a larger proportion of patients with more than $50 \%$ pain relief than the particulate group
[OR 0.81 (95\% Cl: 0.68 - 0.97). The forest plot showing pooled odds ratio for the same is shown in Fig. 5.

\section{Heterogeneity}

While analyzing the primary outcome, a sensitivity analysis to lower the heterogeneity with "single study removal method" found that study by Park et al (21) contributed maximally to the heterogeneity. After removal of this study from the analysis, the heterogeneity reduced significantly to a value of only $50.02 \%$. The forest plot of the pooled point estimate after removal of this study is shown in Fig. 6. 


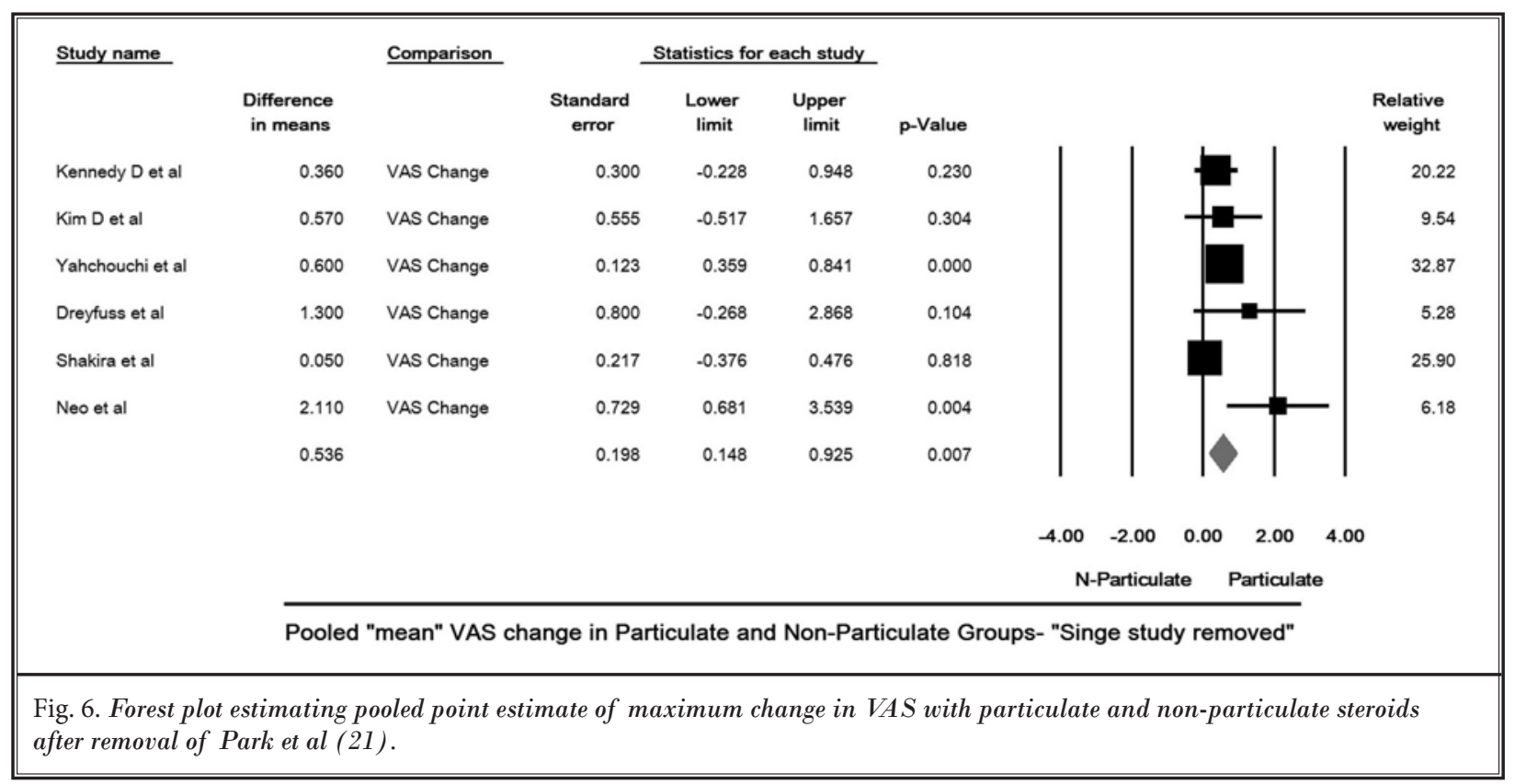

Additionally, in order to explore the heterogeneity a meta-regression evaluating contribution of types of non-particulate steroids was also tried without success due to the small number of studies with individual subsets (less than 10) after using type of steroid as the moderator variable.

\section{Publication Bias}

Funnel plot analysis was conducted. The graphical funnel plot of the included studies for fall in VAS score appeared to be symmetrical (Fig. 7). The publication bias was further quantified using the Egger's test. The intercept was found at $2.287(P=0.247)$. Hence a significant publication bias is unlikely for the drop of VAS score.

Similarly, the funnel plot for studies reporting frequency of patients with $>50 \%$ relief was constructed and evaluated using the Egger's test. Intercept was found at $3.24(P=0.048)$ (Fig. 8), hence publication bias is likely. It implies that studies showing higher frequency of patients with $>50 \%$ pain relief in the particulate group are likely to have been preferentially published in the presently available scientific literature.

\section{Risk of Bias and Assessment of Quality of Evidence}

Risk of bias was assessed using Cochrane criterion (Fig. 9). The systematic review and quality of evidence was assigned based on best evidence synthesis. The meta-analysis as per ASIPP grading is best categorized into Level II evidence, as out of 7 trials only 2 studies are moderate to high quality randomized controlled trials and other 5 trials are retrospective studies.

\section{Discussion}

This systematic review and meta-analysis was conducted to evaluate the efficacy of non-particulate steroids with particulate steroids in patients receiving epidural steroid injections for back pain. Results showed that use of particulate steroids was associated with only a small $(8 \%)$, though statistically significant, decrease in VAS as compared to baseline VAS of $5-6$. Our systematic review of 7 trials revealed Level II evidence, as only 2 studies were moderate to high quality randomized controlled trials, 2 were low to moderate quality, and 3 trials were retrospective studies. Further, data were insufficient to conduct the meta-analysis on the safety profile of the particulate and non-particulate groups.

Kim et al found a smaller mean decrease in VAS for the non-particulate group $(-19.7 \%)$ versus the particulate group (-27.2\%) (23). Similarly Dreyfuss et al and Kennedy et al showed greater improvement with the use of particulate steroids $(24,32)$. Although all these studies showed trends favoring the particulate steroids, neither of the studies could demonstrate statistical significance. Park et al (21) was the only study which showed statistically significant improvement in VAS scores with triamcinolone compared to dexamethasone. 
Particulate vs Non-Particulate Steroids for Transforaminal Epidural Steroid Injection
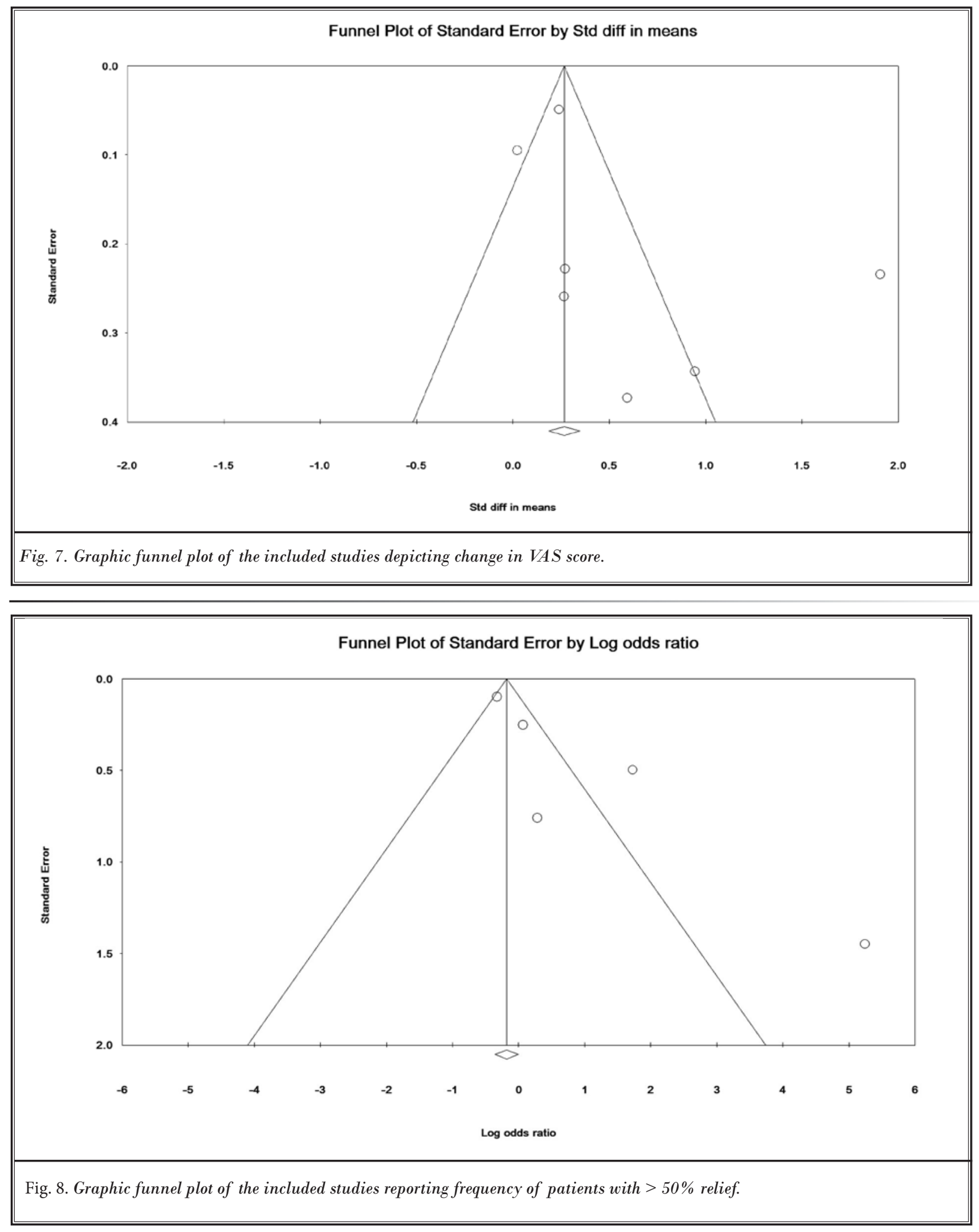
Although this difference in values may seem advantageous at first glance, one must consider its clinical relevance. This increased pain relief of merely VAS score of 1 comes at a price of patient safety. Unfortunately, trials comparing outcomes of particulate versus non-particulate steroids have been limited, with inconsistent safety outcomes (21-24,31-33). Out of 7 studies enrolled, only a single trial of 60 patients receiving dexamethasone or methylprednisolone in lumbar translaminar epidural injection recorded complications (23). On the other hand, the literature is replete with multiple isolated case reports of adverse events. This becomes important in the light of increasing numbers of complications like paralysis, stroke, and even death, which are actually debilitating and often irreversible following

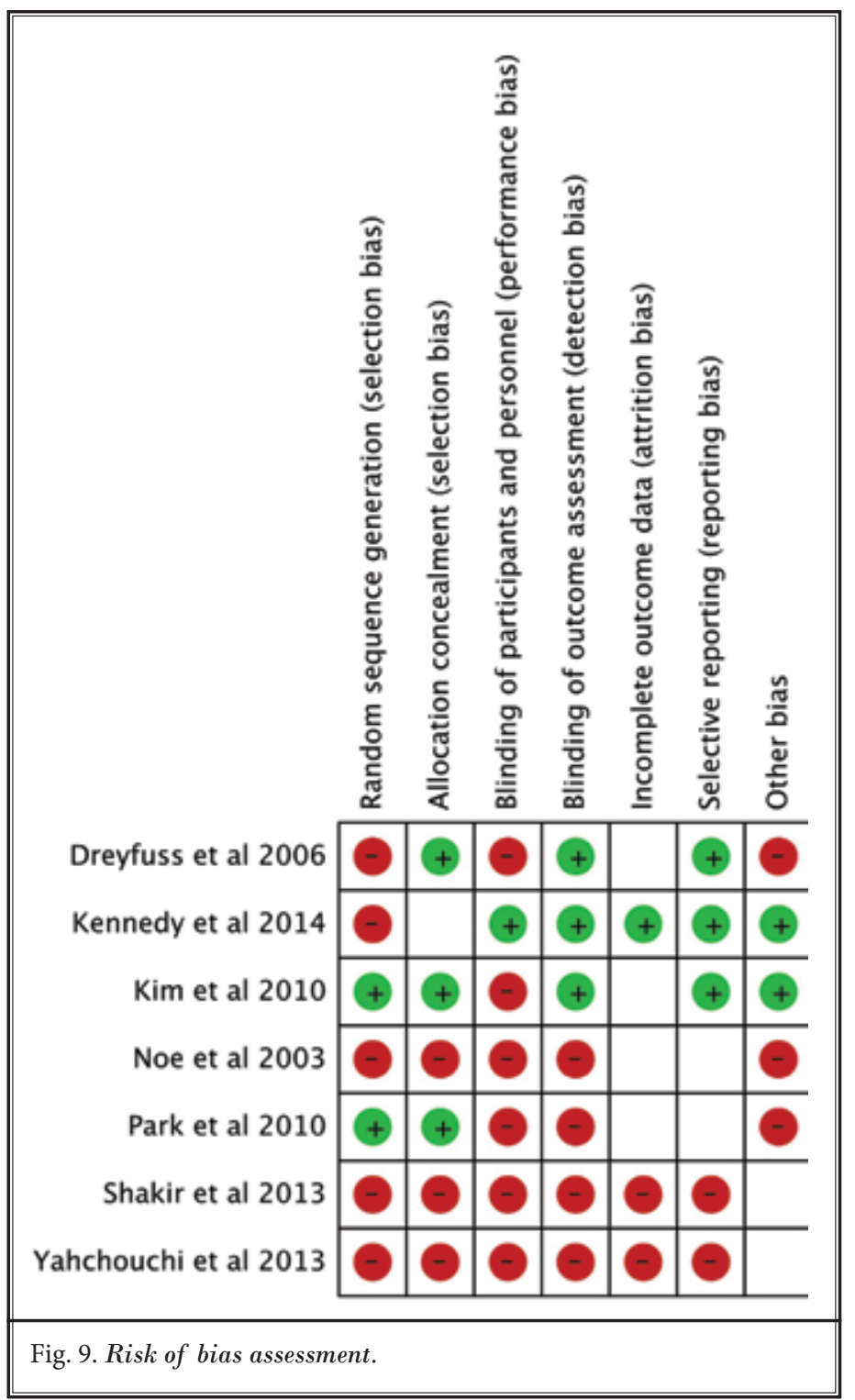

the use of particulate steroids (38-42).

These rare, but potentially devastating, complications of epidural steroid injections have an undefined incidence rate because clinical trials generally have not been well designed and epidemiologic safety data have not been routinely collected (44). In the absence of trials designed to detect rare adverse events due to epidural steroid injections, some useful data have come from a national survey of physician members of the American Pain Society (APS) (43). Of 1,340 surveyed physicians, $21.4 \%$ responded, revealing 78 total epidural steroid injection complications in patients receiving cervical transforaminal epidural steroid injections. Serious complications included 16 brain infarcts, 12 spinal cord infarcts, and 2 combined brain/spinal cord infarcts; death occurred in 13 cases. Corticosteroids were used in 70 of the cases with reported complications. The reported corticosteroids included triamcinolone, betamethasone, and methylprednisolone, which were associated with $10 \%, 11 \%$, and $79 \%$ of complications, respectively.

This concern had prompted the Federal Drug Administration (FDA) to review cases in the FDA Adverse Event Reporting System (FAERS) database and in the medical literature. In a recent FDA Drug Safety Communication, the FDA has contraindicated the use of epidural steroid injections through the transforaminal route for cervical pain (44). However, particulate steroids could be used for lumbar transforaminal epidural steroid injections as the transforaminal area in this region is wider than in the cervical region. Further, it has been seen that injuries following non-particulate injections were temporary, whereas paraplegia after particulate steroids were permanent. Therefore, non-particulate steroids (e.g., dexamethasone) should be used for the initial injection in lumbar transforaminal epidural injections.

Another reason postulated for the high incidence of complications is inappropriate needle positioning. Several studies suggest that the incidence of inappropriate needle position may be as high as $30 \%$ when lumbar epidural steroid injections are placed blindly using the loss of resistance to air technique. This can result in a variable treatment success rate. So to 
increase the validity of our results, we restricted our inclusion criteria to studies that involved administration of epidural steroids using a fluoroscope $(45,46)$.

A study that enrolled 163 patients to receive methylprednisolone, triamcinolone, or dexamethasone in the epidural space for pain relief for sciatica associated with lumbar disc herniation was excluded as the authors used a blind technique to locate the space (47).

We analyzed maximum change in VAS irrespective of the time period as the primary end point as our target was to analyze best possible pain relief reported with use of both particulate and non-particulate steroids. There are limited studies with direct comparisons between particulate and non-particulate steroids and more so show a wide variability in outcome assessment. The majority of the included trials in the analysis evaluated change in pain scores as the primary outcome, therefore change in VAS as the primary outcome increased the generalizability and decreased the heterogeneity. Data were available for 4 studies at one month, one at 2 months, and one at 6 months. In the present meta-analysis various factors could have contributed to the heterogeneity. Variation in pain rating scales in the different trials mandates conversion of different pain-rating scales increasing the heterogeneity. However previous studies have consistently determined that there is a high correlation between pain-rating scales, and scores derived from different scales are often combined in meta-analyses, including those evaluating epi- dural steroid injections $(48,49)$. Techniques of injections and dosage of the steroid used suffer significant variations from center to center. Debating this point, recent reviews have concluded that minor variations in practice are likely to have no significant effect on outcome $(42,44)$. For example, increasing the particulate-steroid dose of more than $40 \mathrm{mg}$ appears to provide no added benefit. But the conglomeration of these different factors (e.g., injection type and number, dose, volume) may have a cumulative effect.

As a result the heterogeneity in the initial evaluation was $90.59 \%$. The above likely variation is further highlighted by the fact that the removal of a single study by Park et al (from South Korea) (21) lowered the heterogeneity to a moderate level of $50.02 \%$.

Although there are no standard guidelines regarding the minimum number of studies needed to perform a meta-analysis, analyses of limited trials do exist and generally agree with longer-term results.

To conclude, there is limited evidence in literature comparing particulate and non-particulate steroids for epidural injection, more so with regard to the evaluation of complications. The available literature suggests that particulate steroids offer a slightly better VAS as compared to non-particulate steroids and clinicians need to weigh the advantage offered by this small difference with the complications reported in the literature with use of particulate steroids. 
Appendix 1. Sources of bias.

\begin{tabular}{|l|l|l|}
\hline A & 1. Was the method of randomization adequate? & Yes/No/Unsure \\
\hline B & 2. Was the treatment allocation concealed? & Yes/No/Unsure \\
\hline C & Was knowledge of the allocated interventions adequately prevented during the study? & \\
\hline & 3. Was the patient blinded to the intervention? & Yes/No/Unsure \\
\hline & 4. Was the care provider blinded to the intervention? & Yes/No/Unsure \\
\hline & 5. Was the outcome assessor blinded to the intervention? & Yes/No/Unsure \\
\hline D & Were incomplete outcome data adequately addressed? & \\
\hline & 6. Was the drop-out rate described and acceptable? & Yes/No/Unsure \\
\hline & 7. Were all randomized participants analysed in theGroup to which they were allocated? & Yes/No/Unsure \\
\hline E & 8. Are reports of the study free of suggestion of selective outcome reporting? & Yes/No/Unsure \\
\hline F & Other sources of potential bias: & \\
\hline & 9. Were the groups similar at baseline regarding the most important prognostic indicators? & Yes/No/Unsure \\
\hline & 10. Were co-interventions avoided or similar? & Yes/No/Unsure \\
\hline & 11. Was the compliance acceptable in all groups? & Yes/No/Unsure \\
\hline & 12. Was the timing of the outcome assessment similar in all groups? & Yes/No/Unsure \\
\hline
\end{tabular}

Appendix 2. ASIPP grading of evidence.

\begin{tabular}{|c|c|}
\hline Level I & $\begin{array}{c}\text { Evidence obtained from multiple relevant high quality randomized controlled trials } \\
\text { or } \\
\text { Evidence obtained from multiple high quality diagnostic accuracy studies }\end{array}$ \\
\hline Level II & $\begin{array}{l}\text { Evidence obtained from at least one relevant high quality randomized controlled trial or multiple relevant moderate or low } \\
\qquad \text { quality randomized controlled trials } \\
\text { or actence obtained from at least one high quality diagnostic accuracy study or multiple moderate or low quality diagnostic } \\
\text { accuracy studies }\end{array}$ \\
\hline Level III & $\begin{array}{l}\begin{array}{l}\text { Evidence obtained from at least one relevant moderate or low quality randomized controlled trial study } \\
\text { or }\end{array} \\
\begin{array}{r}\text { Evidence obtained from at least one relevant high quality non-randomized trial or observational study with multiple } \\
\text { moderate or low quality observational studies }\end{array} \\
\text { Or Evidence obtained from at least one moderate quality diagnostic accuracy study in addition to low quality studies }\end{array}$ \\
\hline Level IV & $\begin{array}{c}\text { Evidence obtained from multiple moderate or low quality relevant observational studies } \\
\text { or } \\
\begin{array}{c}\text { Evidence obtained from multiple relevant low quality diagnostic accuracy studies } \\
\text { studies } \\
\text { or }\end{array} \\
\text { Evidence obtained from multiple relevant low quality diagnostic accuracy studies }\end{array}$ \\
\hline Level V & Opinion or consensus of large group of clinicians and/or scientists. \\
\hline
\end{tabular}




\section{References}

1. Hoy D, Bain C, Williams G, March L, Brooks P, Blyth F, Woolf A, Vos T, Buchbinder R. A systematic review of the global prevalence of low back pain. Arthritis Rheum 2012; 64:2028-2037.

2. Hogg-Johnson S, van der Velde G, Carroll L, Holm LW, Cassidy JD, Guzman J, Cote PD, Haldeman S, Ammendolia C, Carragee E, Hurwitz E, Nordin M, Peloso $P$. The burden and determinants of neck pain in the general population: Results of the bone and joint decade 2000-2010 task force on neck pain and its associated disorders. Spine 2008; 33:S39-S51.

3. Kobayashi S, Takeno K, Yayama T, Awara K, Miyazaki T, Guerrero A, Baba $H$. Pathomechanisms of sciatica in lumbar disc herniation: Effect of peri radicular adhesive tissue on electrophysiological values by an intraoperative straight leg raising test. Spine 2010; 35:2004-2014.

4. Devor M, Govrin-Lippmann R, Raber P. Corticosteroids suppress ectopic neural discharge originating in experimental neuromas. Pain1985; 22:127-137.

5. Johansson A, Hao J, Sjolund B. Local corticosteroid application blocks transmission in normal nociceptive C-fibers. Acta Anaesthesiol Scand 1990; 34:335-338.

6. Abraham G, Demiraj F, Ungemach FR. Comparison of the hypothalamic-pituitary-adrenal axis susceptibility upon single-dose i.m. depot versus long-acting i.v. triamcinolone acetonide therapy: A direct pharmacokinetic correlation. J Endocrinol 2006; 191:491-496.

7. Provenzano DA, Fanciullo G. Cervical transforaminal epidural steroid injections: Should we be performing them? Reg Anesth Pain Med 2007; 32:168.

8. Benzon HT, Chew TL, McCarthy RJ, Benzon HA, Walega DR. Comparison of the particle sizes of different steroids and the effect of dilution: A review of the relative neurotoxicities of the steroids. Anesthesiology 2007; 106:331-338.

9. Glaser SE, Falco F. Paraplegia following a thoracolumbar transforaminal epidural steroid injection. Pain Physician 2005; 8:309-314.

10. Houten JK, Errico TJ. Paraplegia after lumbosacral nerve root block: Report of three cases. Spine ] 2002; 2:70-75.

11. Huntoon MA, Martin DP. Paralysis after transforaminal epidural injection and previous spinal surgery. Reg Anesth Pain Med 2004; 29:494-495.
12. Kennedy DJ, Dreyfuss P, Aprill CN, Bogduk N. Paraplegia following image-guided transforaminal lumbar spine epidural steroid injection: Two case reports. Pain Med 2009; 10:1389-1394.

13. Lyders EM, Morris PP. A case of spinal cord infarction following lumbar transforaminal epidural steroid injection: MR imaging and angiographic findings. Am ] Neuroradiol 2009; 30:1691-1693.

14. Somayaji HS, Saifuddin A, Casey AT, Briggs TW. Spinal cord infarction following therapeutic computed tomographyguided left L2 nerve root injection. Spine 2005; 30:E106-E108.

15. Wybier M. Transforaminal epidural corticosteroid injections and spinal cord infarction. Joint Bone Spine 2008; 75:523525 .

16. Wybier M, Gaudart S, Petrover D, Houdart E, Laredo JD. Paraplegia complicating selective steroid injections of the lumbar spine. Report of five cases and review of the literature. Eur Radiol 2010; 20:181189.

17. Chang Chien GC, Candido KD, Knezevic NN. Digital subtraction angiography does not reliably prevent paraplegia associated with lumbar transforaminal epidural steroid injection. Pain Physician 2012; 15:515-523.

18. Rozin L, Rozin R, Koehler SA, Shakir A, Ladham S, Barmada M, Dominick J, Wecht $\mathrm{CH}$. Death from transforaminal epidural steroid nerve root block $\left(\mathrm{C}_{7}\right)$ due to perforation of the left vertebral artery. Am J Forensic Med Pathol 2003; 24:351355.

19. Tiso RL, Cutler T, Catania JA, Whalen K. Adverse central nervous system sequelae after selective transforaminal block: The role of corticosteroids. Spine ] 2004; 4:468-474.

20. Derby R, Lee S, Date E, Lee J, Lee C. Size and aggregation of corticosteroids used for epidural injections. Pain Med 2008; 9:227-234.

21. Park C, Lee S, Kim B. Comparison of the effectiveness of lumbar transforaminal epidural injection with particulate and nonparticulate corticosteroids in lumbar radiating pain. Pain Med 2010; 11:16541658 .

22. Noe C, Haynsworth R Jr. Comparison of epidural Depo-Medrol vs. aqueous betamethasone in patients with low back pain. Pain Pract 2003; 3:222-225
23. Kim D, Brown J. Efficacy and safety of lumbar epidural dexamethasone versus methylprednisolone in the treatment of lumbar radiculopathy: A comparison of soluble versus particulate steroids. Clin J Pain 2011; 27:518-522.

24. Dreyfuss P, Baker R, Bogduk N. Comparative effectiveness of cervical transforaminal injections with particulate and nonparticulate corticosteroid preparations for cervical radicular pain. Pain Med 2006; 7:237-242.

25. Moher D, Liberati A, Tetzlaff J, Altman DG. The PRISMA statement for reporting systematic reviews and meta-analyses of studies that evaluate healthcare interventions: Explanation and elaboration. BMJ 2009; 339:b270o.

26. Furlan AD, Pennick V, Bombardier C, van Tulder M; Editorial Board CBRG. 2009 updated method guidelines for systematic reviews in the Cochrane Back Review Group. Spine (Phila Pa 1976) 2009; 34:1929-1941.

27. Manchikanti L, Falco FJ, Benyamin RM, Kaye AD, Boswell MV, Hirsch JA. A modified approach to grading of evidence. Pain Physician 2014; 17:E319-E325.

28. P Choi S, Rodseth R, McCartney CJL. Effects of dexamethasone as a local anaesthetic adjuvant for brachial plexus block: A systematic review and meta-analysis of randomized trials. Br JAnaesth 2014; 112:427-439.

29. Higgins J, Deeks J. Selecting studies and collecting data. Cochrane Handbook for Systematic Reviews of Interventions Version 510 (updated March 2011). The Cochrane Collaboration, 2011. Available at: www.cochrane-handbook.org. Accessed October 1, 2014.

30. Lee JW, Park KW, Chung SK, Yeom JS, Kim KJ, Kim HJ, Kang HS. Cervical transforaminal epidural steroid injection for the management of cervical radiculopathy: A comparative study of particulate versus nonparticulate steroids. Skeletal Radiol 2009; 38:1077-1082.

31. El-Yahchouchi C, Geske JR, Carter RE, Diehn FE, Wald JT, Murthy NS, Kaufmann TJ, Thielen KR, Morris JM, Amrami KK, Maus TP. The noninferiority of the nonparticulate steroid dexamethasone vs the particulate steroids betamethasone and triamcinolone in lumbar transforaminal epidural steroid injections. Pain Med 2013; 13:1650-1657. 
32. Kennedy DJ, Plastaras C, Casey E. Comparative effectiveness of lumbar transforaminal epidural steroid injections with particulate versus non particulate corticosteroids for lumbar radicular pain due to intervertebral disc herniation: A prospective, randomized, double-blind trial. Pain Medicine 2014; 15:548-555.

33. Shakir A, Ma V, Mehta B. Comparison of pain score reduction using triamcinolone vs. dexamethasone in cervical transforaminal epidural steroid injections. Am J Phys Med Rehabil 2013; 92:768Y775.

34. Cano WG. Is the particulate effect real? Comparison of the effectiveness, side effects and complication rate of the low particulate steroid dexamethasone vs. two high particulate steroids, triamcinolone and methylprednisolone when used in lumbar epidural injections. Pain Medicine 2010; 11:1571-1578.

35. Smith MB, Rielly L, Bezucha S, Gaskin C, Brewer RP. Dexamethasone versus methylprednisolone for transforaminal cervical epidural corticosteroid injections: Comparative study. Pain Medicine 2010; 11:1583-1584.

36. O'Donnell C, Cano WG, Eramo G. Comparison of triamcinolone to dexamethasone in the treatment of low back and leg pain via lumbar transforaminal epidural steroid injection. The Spine Journal 2008; 8:65S.

37. Haley T, Cano W, O'Donnell C. Comparison of triamcinolone to dexamethasone in the treatment of low back and radicular pain via lumbar transforaminal epidural steroid injection. Pain Medicine 2009; 10:950.

38. Rathmell JP, Aprill C, Bogduk N. Cervical transforaminal injection of steroids. Anesthesiology 2004; 100:1595-1600.

39. Houten JK, Errico TJ. Paraplegia after lumbosacral nerve root block: Report of three cases. Spine J 2002; 2:70-75.

40. Kennedy DJ, Dreyfuss P, Aprill CN, Bogduk N. Paraplegia following imageguided transforaminal lumbar spine epidural steroid injection: Two case reports. Pain Med 2009; 10:1389-1394.

41. Cohen SP, Bicket MC, Jamison D, Wilkinson I, Rathmell JP. Epidural steroids: A comprehensive, evidence-based review. Reg Anesth Pain Med 2013; 38:175200.

42. Scanlon GC, Moeller-Bertram T, Romanowsky SM, Wallace MS. Cervical transforaminal epidural steroid injections: More dangerous than we think? Spine 2007; 32:1249-1256.

43. MacVicar J, King W, Landers MH, Bogduk N. The effectiveness of lumbar transforaminal injection of steroids: A comprehensive review with systematic analysis of the published data. Pain Med 2013; 14:14-18.

44. Epidural Steroid Injections (ESI) and the Risk of Serious Neurologic Adverse Reactions. U.S. Food and Drug Administration. Meeting of the Anesthetic and Analgesic Drug Products Advisory Committee, November 23-24, 2014. www.fda. gov/downloads/AdvisoryCommittees/ CommitteesMeetingMaterials/Drugs/
AnestheticAndAnalgesicDrugProductsAdvisoryCommittee/UCM422692.pdf.

45. Bartynski WS, Grabovac SZ, Rothfus WE. Incorrect needle position during lumbar epidural steroid administration: Inaccuracy of loss of air pressure resistance and requirement of fluoroscopy and epidurography during needle insertion. Am J Neuroradiol 2005; 26:502-505.

46. Liu SS, Melmed AP, Klos JW, Innis CA. Prospective experience with a 20-gauge Tuohy needle for lumbar epidural steroid injections: Is confirmation with fluoroscopy necessary? Reg Anesth Pain Med 2001; 26:143-146.

47. Datta R, Upadhyay KK. A Randomized clinical trial of three different steroid agents for treatment of low backache through the caudal route. MJAFI 2011; 67:25-33. 48. Hjermstad MJ, Fayers PM, Haugen DF, Caraceni A, Hanks GW, Loge JH, Fainsinger R, Aass N, Kaasa S; European Palliative Care Research Collaborative (EPCRC). Studies comparing numerical rating scales, verbal rating scales, and visual analogue scales for assessment of pain intensity in adults: A systematic literature review. J Pain Symptom Manage 2011; 41:1073-1093.

49. Ponce de Leon S, Lara-Muñoz C, Feinstein AR, Wells CK. A comparison of three rating scales for measuring subjective phenomena in clinical research. II. Use of experimentally controlled visual stimuli. Arch Med Res 2004; 35:157162. 